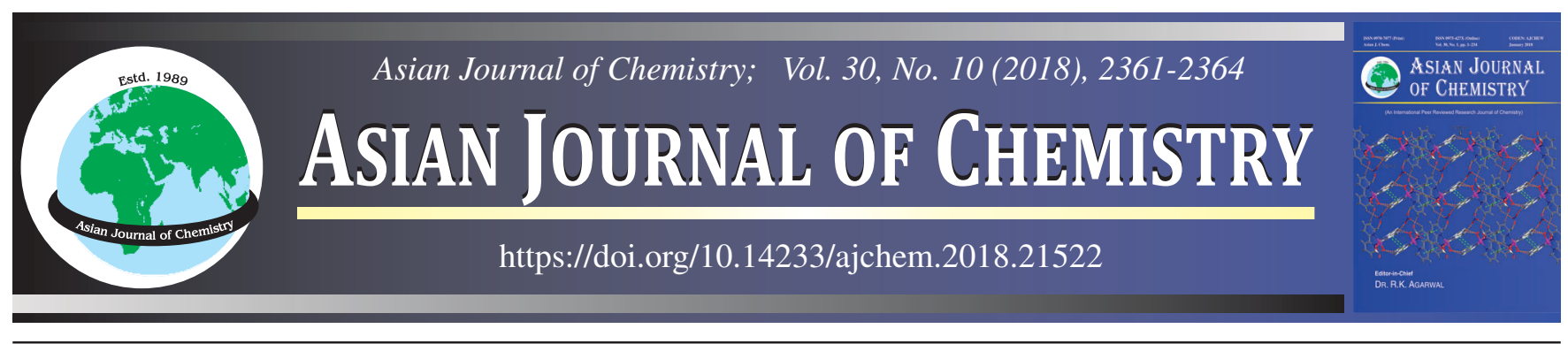

\title{
Synthesis and Antimicrobial Assay of Some Novel 4-Thiazolidinone Derivatives Possessing Benzofuran, Quinoline and Pyrazole Moieties
}

\author{
M. IDREES ${ }^{1, *}$, Y.G. BODKHE ${ }^{2}$ and N.J. SIDDIQUI ${ }^{1}$
}

${ }^{1}$ Department of Chemistry, Government Institute of Science, Nagpur-440 001, India

${ }^{2}$ Department of Chemistry, Government Science College, Gadchiroli-442 605, India

*Corresponding author: E-mail: idreesshaikh.2009@gmail.com

Received: 16 June 2018;

Accepted: 20 July 2018;

Published online: 31 August 2018;

AJC-19075

In this study, simple, easy and convenient syntheses of six novel 4-thiazolidinone derivatives (3a-f) bearing benzofuran, quinoline and pyrazole moieties have been described. In the first step, six different carbohydrazides (2a-f) were synthesized by reacting 5-(benzofuran2-yl)-1-phenyl-1H-pyrazole-3-carbohydrazide (2) with six different 2-( $p$-tolyloxy)quinoline-3-carbaldehyde (1a-f). Similarly, in second step, 5-(benzofuran-2-yl)-N'-(2-(2-( $p$-tolyloxy) substituted quinolin-3-yl)-4-oxothiazolidin-3-yl)-1-phenyl-1H-pyrazole-3-carboxamide (3a-f) was prepared in excellent yield through the interaction of compounds $\mathbf{2 a - f}$ with thioglycolic acid in presence of anhydrous zinc chloride. Structural identifications of products $\mathbf{2 a}$ and $\mathbf{3 a}$ are reported on the basis of IR, ${ }^{1} \mathrm{H}$ NMR, ${ }^{13} \mathrm{C}$ NMR and mass spectra and the analytical data confirms the structure of title compounds. Further, these new products have been assayed for their antimicrobial screening against $S$. aureus and E. coli as the two selected bacterial strains and two fungi such as $C$. albicans and A. niger using paper disc diffusion method. Antimicrobial screening revealed that the compounds are good antibacterial agents but found to be inactive against fungi.

Keywords: Quinoline, Carbohydrazides, Thiazolidinone, Pyrazole, Antibacterial activity.

L

\section{INTRODUCTION}

The synthesis of polysubstituted quinoline and its derivatives is the focus of a large number of pharmacological studies because of their wide range of biological applications. The quinoline moiety constitutes the main framework of several natural products such as Montelukast and Skimmianine. Quinoline was synthesized by Vilsmeier-Haack reagent which is a versatile reagent used in various synthetic transformation [1]. Quinine, amodiaquine, piperaquine, orimaquine, mefloquine and chloroquine are used as antimalarial drugs mainly consist quinoline moiety [2]. Quinoline nucleus shows good antitumor [3] and antifungal [4] activities. It is also reported that coordination polymer of quinoline ligand too showed antimicrobial activity [5]. Antimicrobial screening and molecular docking studies of some triazoloquinazolinone [6] has also been studied.

On the other hand, thiazolidinones are also an important class of heterocyclic compounds which has been classified as 2,4,5thiazolidinones depending on the position of carbonyl group. Out of these 4-thiazolidinone is a five member ring with carbonyl group at fourth position and methylene carbon atom at fifth position is found to be more nucleophilic, hence, electrophilic substitution may occur at this position. Thiazolidinone scaffold is a better pharmacophore showing various biological activities such as anti-inflammatory, analgesic [7], antitubercular [8-10], antifungal [9], inhibitory [11], antioxidant [12,13], antihyperglycemic [14], antimycobacterial [15], antibacterial [16-18], cytotoxic [19,20], antiviral [21], antiparkinsnian [22], antinfective [23]. Toxoplasma gondii infection was studied for 4-thiazolidinone [24]. This amazing array of applications and ubiquitous biological importance of quinoline along with thiazolidinones led us to synthesize a new series of 4-thiazolidinone analogues containing benzofuran, quinoline and pyrazole moiety and evaluate their antimicrobial activities.

\section{EXPERIMENTAL}

The melting points of newly synthesized compounds were determined in open capillary paraffin oil bath and found to be uncorrected. ${ }^{1} \mathrm{H}$ NMR spectra was recorded on Bruker AM 400 instrument using tetramethylsilane as an internal reference

This is an open access journal, and articles are distributed under the terms of the Creative Commons Attribution-NonCommercial 4.0 International (CC BY-NC 4.0) License, which allows others to copy and redistribute the material in any medium or format, remix, transform, and build upon the material, as long as appropriate credit is given and the new creations are licensed under the identical terms. 
and DMSO- $d_{6}$ as solvent. IR spectra were recorded on a Shimadzu IR 8400 Spectrophotometer with the frequency ranging from $4000-400 \mathrm{~cm}^{-1}$. Mass spectra were obtained with a Waters Micro mass Q-TOF Micro, Mass Spectrophotometer. Elemental analysis was performed using Thermo Scientific (Flash-2000). All the chemicals used were of AR grade of Merck, S.D. Fine and Aldrich.

General procedure for synthesis of 5-(benzofuran-2yl)- $\mathrm{N}^{\prime}$-((6-methyl-2-(p-tolyloxy)quinolin-3-yl)methylene)1-phenyl-1H-pyrazole-3-carbohydrazide (2a) : 5-(benzofuran-2-yl)-1-phenyl-1H-pyrazole-3-carbohydrazide (2, 0.01 mol) and 6-methyl-2-(p-tolyloxy) quinoline-3-carbaldehyde (1a) were dissolved in ethanol and then 2-3 drops of acetic acid were added and the reaction mixture was refluxed for $2 \mathrm{~h}$. Resulting mass was cooled and poured into crushed ice, filtered and further purified by recrystallization using 1,4-dioxane to give 2a. Similarly, other derivatives 2a-f were synthesized by by applying the same procedure as adopted for the synthesis of $2 \mathbf{a}$ (Scheme-I).

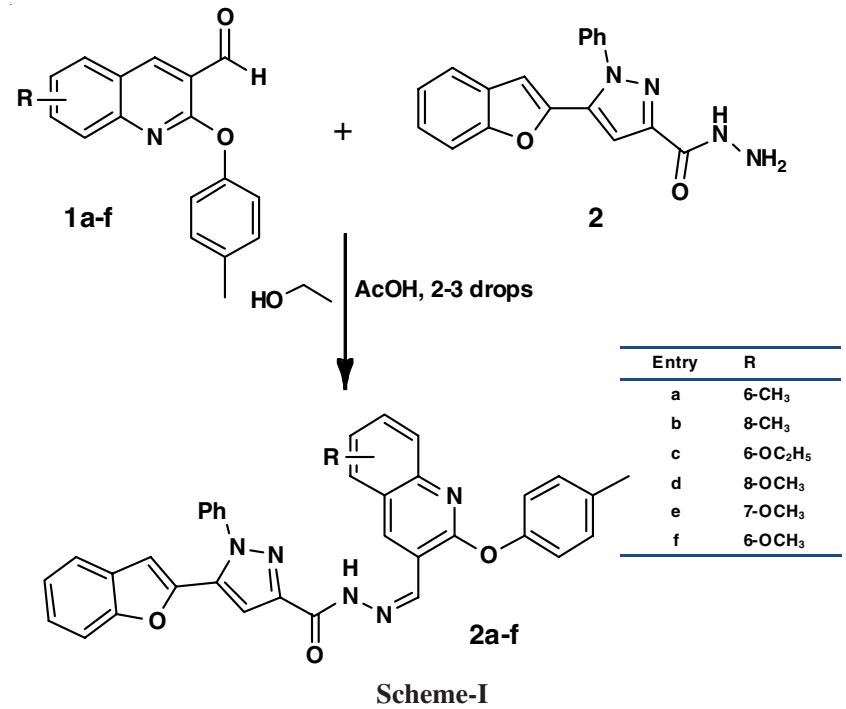

5-(Benzofuran-2-yl)- $\mathrm{N}^{\prime}$-((6-methyl-2-( $p$-tolyloxy)quinolin-3-yl)methylene)-1-phenyl- $1 H$-pyrazole-3-carbohydrazide (2a): Yellow crystalline solid; m.p. $263-265{ }^{\circ} \mathrm{C}$; Yield: $81 \%$; IR ( $\left.\mathrm{KBr}, v_{\max }, \mathrm{cm}^{-1}\right)$ : 3293, 3412, (N-H str.), 3062, 3029 (C-H str., arom.), 2958 (C-H asym. str., aliph.), 2857, 2915 (C-H str. sym., aliphatic), 1688 (C=O str.), 1650-1600 (C=N str.), 1240 (C-O-C sym. str., ether), 1058 (C-O-C asym. str., ether); ${ }^{1} \mathrm{H}$ NMR (DMSO- $d_{6}$ ) $\delta$ ppm: 2.36 (s, $3 \mathrm{H}, \mathrm{Ar}_{-} \mathrm{CH}_{3}$ ), $2.47\left(\mathrm{~s}, 3 \mathrm{H}, \mathrm{CH}_{3}\right.$ attached to quinoline ring), $6.51(\mathrm{~s}, 1 \mathrm{H}$, at $\mathrm{C} 4$ of pyrazole ring), 12.21 (s, 1H, NHCO), 7.14-9.08 (m, 19H, arom. + heterocycl. ring protons); MS: $m / e ~ 577 \mathrm{M}^{+}, 578[\mathrm{M}+\mathrm{H}]^{+}$, $579[\mathrm{M}+2]^{+}, 600[\mathrm{M}+\mathrm{Na}]^{+}$. Elemental analysis $(\%)$ calcd. (found) $\mathrm{C}_{36} \mathrm{H}_{27} \mathrm{~N}_{5} \mathrm{O}_{3}$ : C, 74.85 (74.05); $\mathrm{H}, 4.71$ (4.50); N, 12.12 (12.06).

5-(Benzofuran-2-yl)-N'-((8-methyl-2-( $p$-tolyloxy)quinolin-3-yl)methylene)-1-phenyl-1H-pyrazole-3-carbohydrazide (2b): Yellow crystalline solid; m.p. $234-238^{\circ} \mathrm{C}$; Yield: $88 \%$. Elemental analysis (\%) calcd. (found) $\mathrm{C}_{36} \mathrm{H}_{27} \mathrm{~N}_{5} \mathrm{O}_{3}: \mathrm{N}, 12.12$ (12.16).

5-(Benzofuran-2-yl)- $\mathrm{N}^{\prime}$-((6-ethoxy-2-(p-tolyloxy)quinolin-3-yl)methylene)-1-phenyl-1H-pyrazole-3-carbohydrazide (2c): Yellow crystalline solid; m.p. $260-264{ }^{\circ} \mathrm{C}$;
Yield: $88 \%$. IR (KBr, $\left.v_{\max }, \mathrm{cm}^{-1}\right): 3944,3392,3318,3147(\mathrm{~N}-\mathrm{H}$ str.), 3061 (C-H str., arom.), 2956, 2920 (C-H asym. str., aliph.), 2803 (C-H str. sym., aliph.), 1689 (C=O str. amide), 1580, 1505 $(\mathrm{C}=\mathrm{N}), 1247$ (C-O-C sym. str., ether), 1087, 1037 (C-O-C asym. str., ether); Elemental analysis (\%) calcd. (found) $\mathrm{C}_{37} \mathrm{H}_{29} \mathrm{~N}_{5} \mathrm{O}_{4}$ : N, 11.53 (11.58).

5-(Benzofuran-2-yl)-N'-((8-methoxy-2-(p-tolyloxy)quinolin-3-yl)methylene)-1-phenyl-1 $H$-pyrazole-3-carbohydrazide (2d): Yellow crystalline solid; m.p. $228-232{ }^{\circ} \mathrm{C}$, Yield: $83 \%$. Elemental analysis (\%) calcd. (found) $\mathrm{C}_{36} \mathrm{H}_{27} \mathrm{~N}_{5} \mathrm{O}_{4}$ : N, 11.80 (11.84).

5-(Benzofuran-2-yl)- $\mathrm{N}^{\prime}$-((7-methoxy-2-( $p$-tolyloxy)quinolin-3-yl)methylene)-1-phenyl- $1 \mathrm{H}$-pyrazole-3-carbohydrazide (2e) : Yellow crystalline solid; m.p. $228-231{ }^{\circ} \mathrm{C}$; Yield: $79 \%$. Elemental analysis (\%) calcd. (found) $\mathrm{C}_{36} \mathrm{H}_{27} \mathrm{~N}_{5} \mathrm{O}_{4}$ : N, 11.80 (11.88).

5-(Benzofuran-2-yl)- $\mathrm{N}^{\prime}$-((6-methoxy-2-( $p$-tolyloxy)quinolin-3-yl)methylene)-1-phenyl- $1 \mathrm{H}$-pyrazole-3-carbohydrazide (2f): Yellow crystalline solid; m.p. $258-261^{\circ} \mathrm{C}$, Yield: $79 \%$. Elemental analysis (\%) calcd. (found) $\mathrm{C}_{36} \mathrm{H}_{27} \mathrm{~N}_{5} \mathrm{O}_{4}: \mathrm{N}$, 11.80 (11.88).

Synthesis of 5-(benzofuran-2-yl)- $N^{\prime}$-(2-(6-methyl-2-( $p$ tolyloxy) quinoline-3-yl)-4-oxothiazolidin-3-yl)-1-phenyl$1 \mathrm{H}$-pyrazole-3-carboxamide (3a): To a mixture of 5-(benzofuran-3-yl)-N'-((6-methyl-2-(p-tolyloxy)quinolin-3-yl)methylene)-1-phenyl-4,5-dihydro- $1 H$-pyrazole-3-carbohydrazide) (2a, $0.02 \mathrm{~mol}$ ) and thioglycolic acid in 1,4-dioxane, anhydrous $\mathrm{ZnCl}_{2}$ was added and then the reaction content was refluxed for $8 \mathrm{~h}$. The reaction mixture was kept overnight after addition of $10 \%$ sodium bicarbonate to neutralize thioglycolic acid. The solution was stirred and product was separated out was filtered, washed and recrystallized from 1,4-dioxane to get $\mathbf{3 a}$. Brown, crystalline solid; m.p. $178-180{ }^{\circ} \mathrm{C}$; Yield: $85 \%$. IR $\left(\mathrm{KBr}, v_{\max }, \mathrm{cm}^{-1}\right): 3228(\mathrm{~N}-\mathrm{H}$ str. amide), 3061 (C-H str., arom.), 1005,1027(C-H i.p.def, arom.), 808 (C-H o.o.p. def. arom.), 1498, 1527 (C=C str. arom.), 1595 ( $\mathrm{C}=\mathrm{N}$ str., quinoline ring), 1673 (C=O amide str.), 1027, 1073 (C-O-C asym. str., ether), 1257, 1208 (C-O-C sym. str., ether), 1673 (C=O str. thiazolidinone ring), 1208 (C-N str. thiazolidinone ring), 696 (C-S-C str. thiazolidinone ring). ${ }^{1} \mathrm{H}$ NMR (DMSO- $\left.d_{6}\right) \delta \mathrm{ppm}: 2.35$ (s, 6H, two $\mathrm{CH}_{3}$ group attached to two different aromatic ring), 3.58 (s, $2 \mathrm{H}, \mathrm{CH}_{2}$ of thiazolidinone ring), 6.48 (s, $1 \mathrm{H}$, at $\mathrm{C} 2$ of thiazolidinone ring), $6.49(\mathrm{~s}, 1 \mathrm{H}$, at $\mathrm{C} 4$ of pyrazole ring), $8.30(\mathrm{~s}, 1 \mathrm{H}$, at $\mathrm{C} 4$ of quinoline ring), 10.41 (s, 1H, NH of -CONH- linkage), 6.38-7.67 (m, $17 \mathrm{H}$, arom. and heterocycl.). ${ }^{13} \mathrm{C} \mathrm{NMR}(\delta \mathrm{ppm})$ : $21\left(\mathrm{CH}_{3}\right), 38$ ( $\mathrm{C} 2$ of thiazolidinone), 48 ( $\mathrm{C} 5$ of thiazolidinone), $105,106,107,110,121,123,125,127,129,135,139,144,145$, $153,159,167$ (carbon of -CONH). Mass spectra $m / z 652[\mathrm{M}+\mathrm{H}]^{+}$, $674[\mathrm{M}+\mathrm{Na}]^{+}$. Elemental analysis (\%) calcd. (found) $\mathrm{C}_{38} \mathrm{H}_{29} \mathrm{~N}_{5} \mathrm{O}_{4} \mathrm{~S}$ : C, 70.03 (70.08); H, 4.49 (4.54); N, 10.75 (10.72); S, 4.92 (4.98). Similarly, other compounds $\mathbf{3 b - f}$ of this series was prepared by adopting the same procedure followed for compound $\mathbf{3 a}$. Their structures were established on the basis of elemental and physical data (Table-1).

Antimicrobial activity: All the compounds were screened in vitro for their antibacterial and antifungal activities at concentration of $1000 \mu \mathrm{g} / \mathrm{mL}$. Out of all the six synthesized compounds 2a and 3a were then assayed at different concen- 
TABLE-1

PHYSICAL AND ANALYTICAL DATA OF SYNTHESIZED COMPOUNDS 3b-f

\begin{tabular}{|c|c|c|c|c|c|c|c|c|}
\hline \multirow{2}{*}{ Entry } & \multirow{2}{*}{$\mathrm{R}$} & \multirow{2}{*}{ Colour } & \multirow{2}{*}{ Recrys. solvent } & \multirow{2}{*}{ m.p. $\left({ }^{\circ} \mathrm{C}\right)$} & \multirow{2}{*}{ Yield $(\%)$} & \multirow{2}{*}{ m.f. } & \multicolumn{2}{|c|}{ Elemental analysis (\%): Found (calcd.) } \\
\hline & & & & & & & $\mathrm{N}$ & $\mathrm{S}$ \\
\hline 3b & $8-\mathrm{CH}_{3}$ & Brown & 1,4-Dioxane & $184-190$ & 75 & $\mathrm{C}_{38} \mathrm{H}_{29} \mathrm{~N}_{5} \mathrm{O}_{4} \mathrm{~S}$ & $10.82(10.75)$ & $4.91(4.92)$ \\
\hline $3 c$ & $6-\mathrm{OC}_{2} \mathrm{H}_{5}$ & Brown & 1,4-Dioxane & $234-238$ & 80 & $\mathrm{C}_{39} \mathrm{H}_{31} \mathrm{~N}_{5} \mathrm{O}_{5} \mathrm{~S}$ & $10.32(10.27)$ & $4.73(4.70)$ \\
\hline 3d & $8-\mathrm{OCH}_{3}$ & Brown & 1,4-Dioxane & $220-224$ & 76 & $\mathrm{C}_{38} \mathrm{H}_{29} \mathrm{~N}_{5} \mathrm{O}_{5} \mathrm{~S}$ & $10.48(10.49)$ & $4.82(4.80)$ \\
\hline $3 e$ & $7-\mathrm{OCH}_{3}$ & Brown & 1,4-Dioxane & $203-207$ & 75 & $\mathrm{C}_{38} \mathrm{H}_{29} \mathrm{~N}_{5} \mathrm{O}_{5} \mathrm{~S}$ & $10.45(10.49)$ & $4.78(4.80)$ \\
\hline 3f & $6-\mathrm{OCH}_{3}$ & Brown & 1,4-Dioxane & $244-250$ & 75 & $\mathrm{C}_{38} \mathrm{H}_{29} \mathrm{~N}_{5} \mathrm{O}_{5} \mathrm{~S}$ & $10.51(10.49)$ & $4.79(4.80)$ \\
\hline
\end{tabular}

tration ranging from 1000 to $63 \mu \mathrm{g} / \mathrm{mL}$ using disc diffusion method. Initially, stock culture of $S$. aureus and E. coli were revived by inoculating in broth media at $37^{\circ} \mathrm{C}$ for $18 \mathrm{~h}$. The agar plate of nutrient agar media was prepared and sterilized. After the inoculation of bacterial cultural, the discs were dipped in the different concentration of compound, which was prepared in DMSO and placed on the surface of agar plate. All the plates were incubated for $37^{\circ} \mathrm{C}$ for $24 \mathrm{~h}$ and diameter of zone of inhibition were noted in $\mathrm{mm}$. The results were compared with standard drug Chloramphenicol. Same procedure was applied for A. niger and $C$. albicans and results were compared with standard drug Amphotericin.

\section{RESULTS AND DISCUSSION}

Synthetic work was performed as described in Schemes I and II and their purity was checked by TLC. The compounds were obtained in excellent yield and structures have been confirmed by elemental analysis and IR, ${ }^{1} \mathrm{H}$ NMR and mass spectral studies. 2-Chloroquinoline-3-carbaldehyde derivatives were the starting compounds which were prepared by Vilsmeier cyclization [1], which later on reaction with $p$-cresol in presence of $\mathrm{K}_{2} \mathrm{CO}_{3}$ in DMF yielded substituted 2-phenoxyquinoline-3carbaldehyde derivatives (1a-f). Treatment of compounds 1a-f with 5-(benzofuran-2-yl)-1-phenyl-1H-pyrazole-3-carbohydrazide (2) yielded 5-(benzofuran-2-yl)- $\mathrm{N}^{\prime}-((2-(p-$-tolyloxy)substituted quinolin-3-yl)methylene)-1-phenyl - $1 H$-pyrazole3-carbohydrazides (2a-f) as illustrated in Scheme-I.

The IR spectra of compounds 2a and $\mathbf{2 c}$ showed a broad signal of NH at 3293,3412 and $3318 \mathrm{~cm}^{-1}$ respectively. The absorption bands at 1688 and $1689 \mathrm{~cm}^{-1}$ are due to $\mathrm{C}=\mathrm{O}$ stretching also observed. Similarly, peak at 1580 in compound $\mathbf{2 c}$ and $1650-1600 \mathrm{~cm}^{-1}$ in compound $\mathbf{2 a}$ are due to $\mathrm{C}=\mathrm{N}$ stretching in pyrazole ring further supported the structure of compounds 2c and 2a. Molecular ion peaks of $[\mathrm{M}+\mathrm{H}]^{+}$, in mass spectra at 578 for compound $\mathbf{2 a}$ confirmed its molecular weight. ${ }^{1} \mathrm{H}$ NMR spectrum of compound 2a showed two singlet's, one at $2.36 \mathrm{ppm}$ due to three proton of $\mathrm{CH}_{3}$ on aromatic ring, and another at $2.47 \mathrm{ppm}$ due to $\mathrm{CH}_{3}$ group attached to quinoline moiety. Proton present on the pyrazole ring at $\mathrm{C} 4$ carbon gave singlet at $6.51 \mathrm{ppm}$, another downfield singlet appear at 12.21 ppm due to one proton of $\mathrm{NH}$ of $\mathrm{NHCO}$ group and multiplet exhibited in the range of 7.14-9.08 ppm are due to nineteen protons present on aromatic and heterocyclic ring. Thus ${ }^{1} \mathrm{H} N \mathrm{MR}$ spectrum of compound 2a is in good agreement with the number of protons present in the molecular formula $\mathrm{C}_{36} \mathrm{H}_{27} \mathrm{~N}_{5} \mathrm{O}_{3}$.

The resulted compounds $2 \mathrm{a}-\mathrm{f}$ were then reacted with thioglycolic acid in the presence of anhydrous $\mathrm{ZnCl}_{2}$ and cyclized successfully to five-membered 4-thiazolidinones ring (3a-f) in good to moderate yield and were recrystallized by 1,4-dioxane (Table-1). All the synthesized compounds 3a-f was tested for nitrogen and sulphur which gave positive result confirming the presence of these extra elements in thiazolidinone ring.

The IR spectrum of compound 3a showed characteristics absorption bands at $3228 \mathrm{~cm}^{-1}$ due to NH stretch. Another absorption band appeared at $1673 \mathrm{~cm}^{-1}$ assigned due to $\mathrm{C}=\mathrm{O}$ stretching in thiazolidinone ring. Another characteristic band appeared at $696 \mathrm{~cm}^{-1}$ due to C-S-C stretch confirmed the formation of thiazolidinone ring. ${ }^{1} \mathrm{H}$ NMR spectra for compound $\mathbf{3 a}$ exhibited singlet at $2.35 \mathrm{ppm}$ due to six protons of two $\mathrm{CH}_{3}$ group attached to phenyl and quinoline ring. Other signals for aromatic protons appeared at expected region. Singlet at 3.58 and $6.48 \mathrm{ppm}$ for two protons and one proton for $\mathrm{CH}_{2}$ and $\mathrm{CH}$ group, respectively were observed which was absent in compound $\mathbf{2 a}$, this confirms the formation of thiazolidinone ring. A singlet appeared at $8.30 \mathrm{ppm}$ due to one proton of $\mathrm{NH}$ of -CONH- linkage. Singlet due to one proton located at $\mathrm{C} 4$ of quinoline ring was also observed in expected region in compound $\mathbf{3 a}$ as observed for compound 2a. Two characteristics ${ }^{13} \mathrm{C}$ NMR signals appeared at 38 and 48 ppm is assigned due to carbon atom at second and fifth position of thiazolidinone ring and signals due to other aromatic and aliphatic carbons appeared at the expected region. The mass spectra of compound 3a gives a molecular ion peak of $[\mathrm{M}+\mathrm{H}]^{+}$ at 652 and $[\mathrm{M}+\mathrm{Na}]^{+}$at 674 , is in good agreement with the molecular formula $\mathrm{C}_{38} \mathrm{H}_{29} \mathrm{~N}_{5} \mathrm{O}_{4} \mathrm{~S}$.

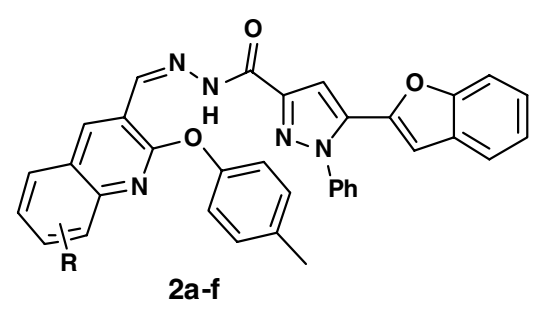

2a-f

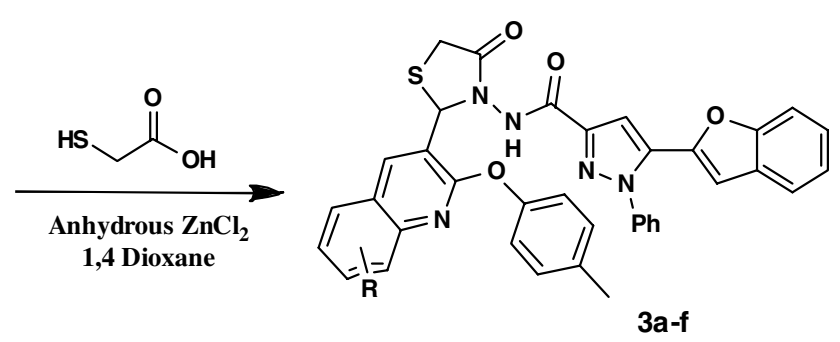

3a-f

\begin{tabular}{ccccccc}
\hline Entry & a & b & c & d & e & f \\
\hline R & $6-\mathrm{CH}_{3}$ & $8-\mathrm{CH}_{3}$ & $6-\mathrm{OC}_{2} \mathrm{H}_{5}$ & $8-\mathrm{OCH}_{3}$ & $7-\mathrm{OCH}_{3}$ & $6-\mathrm{OCH}_{3}$ \\
\hline
\end{tabular}


TABLE-2

ANTIBACTERIAL ACTIVITY OF 2a AND 3a AT DIFFERENT CONCENTRATIONS

\begin{tabular}{|c|c|c|c|c|c|c|}
\hline \multirow{3}{*}{ Conc. $(\mu \mathrm{g} / \mathrm{mL})$} & \multicolumn{6}{|c|}{ Zone of inhibition (mm) } \\
\hline & \multicolumn{3}{|c|}{ Gram-positive: $S$. aureus } & \multicolumn{3}{|c|}{ Gram-negative: E. coli } \\
\hline & Chloramphenicol & $2 a$ & $3 \mathbf{a}$ & Chloramphenicol & $2 a$ & 3a \\
\hline 1000 & 26 & 15 & 12 & 16 & 15 & 17 \\
\hline 500 & 30 & 12 & 13 & 16 & 13 & 17 \\
\hline 250 & 27 & 13 & 12 & 17 & 13 & 14 \\
\hline 125 & 21 & 10 & 10 & 16 & 12 & 10 \\
\hline 63 & 18 & 16 & 11 & 15 & 10 & 10 \\
\hline
\end{tabular}

Antimicrobial activity: The novel synthesized benzofuran, quinoline and pyrazole based carbohydrazide and 4-thiazolidinone derivatives (2a and $\mathbf{3 a}$ ), respectively were screened in vitro for antimicrobial activity at different concentration ranging from 1000 to $63 \mu \mathrm{g} / \mathrm{mL}$, while remaining compounds $3 \mathbf{b}$-f were studied at concentration $1000 \mu \mathrm{g} / \mathrm{mL}$, against bacterial strain S. aureus and $E$. coli. According to the screening results, compounds $\mathbf{3 a}$ and $3 \mathbf{c}$ showed stronger activity at concentration of $1000 \mu \mathrm{g} /$ $\mathrm{mL}$ against $E$. coli. The compound $3 \mathbf{a}$ was found to be inactive against fungal strain $A$. niger and $C$. albicans. All the compounds 3a-f were then tested at the same concen-tration $1000 \mu \mathrm{g} / \mathrm{mL}$. All the series of compound showed good activities towards selected bacteria and found to be inactive for fungi under consideration as shown in Tables 2 and 3.

\begin{tabular}{ccc} 
TABLE-3 & \multicolumn{2}{c}{$\begin{array}{c}\text { TABIT } \\
\text { ANTIBACTERIAL ACTIVITY OF 3a-f AT } 1000 \mu \mathrm{g} / \mathrm{mL}\end{array}$} \\
\hline \multirow{2}{*}{ Entry } & \multicolumn{2}{c}{ Zone of inhibition $(\mathrm{mm})$} \\
\cline { 2 - 3 } & $\begin{array}{c}\text { Gram-positive: } \\
\text { S. aureus }\end{array}$ & $\begin{array}{c}\text { Gram-negative: } \\
\text { E. coli }\end{array}$ \\
\hline 3a & 12 & $\mathbf{1 7}$ \\
3b & 13 & 15 \\
3c & 12 & $\mathbf{1 6}$ \\
3d & 11 & 15 \\
3e & 11 & 14 \\
3f & 12 & 14 \\
Chloramphenicol & $\mathbf{1 8}$ & $\mathbf{1 6}$ \\
\hline
\end{tabular}

\section{Conclusion}

In conclusion, we have reported the synthesis of some new 4-thiazolidinone derivatives bearing benzofuran, quinoline and pyrazole moieties in good yield and characterized by elemental and spectral studies such as IR, ${ }^{1} \mathrm{H}$ NMR and mass spectra. Antimicrobial assay of these synthesized compounds showed better activities for bacteria but inactive against selected fungi.

\section{ACKNOWLEDGEMENTS}

The authors are thankful to The Principal, Government Science College, Gadchiroli, India for providing the research facilities. The authors are also thankful to the Director, SAIF, Punjab University, Chandigarh, India for spectral and elemental analyses. The authors also thank Guru Nanak College of Science, Ballarpur, India for providing the facilities of antimicrobial activity.

\section{CONFLICT OF INTEREST}

The authors declare that there is no conflict of interests regarding the publication of this article.

\section{REFERENCES}

1. R. Singh and A. Srivastava, Med. Chem., 44, 1868 (2005).

2. K. Kaur, M. Jain, R. Reddy and R. Jain, Eur. J. Med. Chem., 45, 3245 (2010); https://doi.org/10.1016/j.ejmech.2010.04.011.

3. S. Jain, V. Chandra, P.K. Jain, K. Pathak, D. Pathak and A. Vaidya, Arab. J. Chem.; https://doi.org/10.1016/j.arabjc.2016.10.009.

4. D.B. Yaakov, Y. Shadkchan, N.A. Dimitrios, P. Kontoyiannis and N. Osherov, J. Antimicrob. Chemother, 72, 2263 (2017); https://doi.org/10.1093/jac/dkx117.

5. X.-Z. Zou, J.-A. Zhang, L.-J. Zhang, Y.-J. Liu, N. Li, Y. Li, S.-C. Wei and M. Pan, Inorg. Chem. Commun., 54, 21 (2015); https://doi.org/10.1016/j.inoche.2015.01.029.

6. T. Elavarasan, D. Bhakiarajand and M. Gopalakrishnan, Der Pharma Chem., 6, 391 (2014)

7. A.K. Jain, A. Vaidya, V. Ravichandran, S.K. Kashaw and R.K. Agrawal, Bioorg. Med. Chem., 20, 3378 (2012); https://doi.org/10.1016/j.bmc.2012.03.069.

8. P. Samadhiya, R. Sharma, S. Srivastava and S.D. Srivastava, Arab. J. Chem., 7, 657 (2014); https://doi.org/10.1016/j.arabjc.2010.11.015.

9. D. Kaminskyy, B. Bednarczyk-Cwynar, O. Vasylenko, O. Kazakova, R. Lesyk, B. Zimenkovsky and L. Zaprutko, Med. Chem. Res., 21, 3568 (2012); https://doi.org/10.1007/s00044-011-9893-9.

10. S. Avdieiev, L. Gera, D. Havrylyuk, R.S. Hodges, R. Lesyk, V. Ribrag, Y. Vassetzky and V. Kavsana, Bioorg. Med. Chem., 22, 3815 (2014); https://doi.org/10.1016/j.bmc.2014.06.046.

11. P.-C. Lv, C.-F. Zhou, J. Chen, P.-G. Liu, K.-R. Wang, W.-J. Mao, H.-Q. Li, Y. Yang, J. Xiong and H.-L. Zhu, Bioorg. Med. Chem., 18, 314 (2010); https://doi.org/10.1016/j.bmc.2009.10.051.

12. V. Kumar, A. Sharma and P.C. Sharma, J. Enzym. Inhib. Med. Chem., 26, 198 (2011); https://doi.org/10.3109/14756366.2010.489897.

13. A. Aly, A. Brown and M. Abdel-Aziz, G. El-Din A.A. Abuo-Rahma, M.F. Radwan, M. Ramadan and A.M. Gamal-Eldeen, J. Heterocycl. Chem., 47, 547 (2010); https://doi.org/10.1002/jhet.290.

14. S. Riyaz, A. Naidu, P. Dubey, Indian J. Chem., 51B, 1396 (2012).

15. R. Patel and S. Park, Chem. Biol. Drug Des., 84, 123 (2014); https://doi.org/10.1111/cbdd.12299.

16. N.B. Patel, V.N. Patel, H.K.R. Patel and J. Patel, Acta Pol. Pharm., 67, 267 (2010).

17. V. Kumar, A. Kumar, S. Sharma and N.P. Singh, Indian J. Chem., 50B, 1496 (2011).

18. K. Mistry and K. Desai, E-J. Chem., 1, 189 (2004); https://doi.org/10.1155/2004/590439.

19. A. Saundane and P. Walmik, J. Chem., Article ID 543815 (2013); https://doi.org/10.1155/2013/543815.

20. R. George, Eur. J. Med. Chem., 47, 377 (2012); https://doi.org/10.1016/j.ejmech.2011.11.006.

21. V. Ravichandran, A. Jain, K. Kumar, H. Rajak and R. Agrawal, Chem. Biol. Drug Des., 78, 464 (2011); https://doi.org/10.1111/j.1747-0285.2011.01149.x.

22. S. Kumar, H. Kaur and A. Kumar, Arab. J. Chem., 5, 475 (2012); https://doi.org/10.1016/j.arabjc.2010.09.014.

23. A. Gupta, R. Singh, P. Sonar and S. Saraf, Biochem. Res. Int., Article ID 8086762 (2016); https://doi.org/10.1155/2016/8086762.

24. A.P. Liesen, T.M. de Aquino, C.S. Carvalho, V.T. Lima, J.M. de Araújo, J.G. de Lima, A.R. de Faria, E.J.T. de Melo, A.J. Alves and E.W. Alves, Eur. J. Med. Chem., 45, 3685 (2010); https://doi.org/10.1016/j.ejmech.2010.05.017.

25. M. Idrees, R.D. Nasare, N.J. Siddiqui, Chem. Sci. Transac., 5, 1090 (2016); https://doi.org/10.7598/cst2016.1323. 